\title{
FINAL REPORT \\ The Effects of Behavioral Change in Response to Acoustic Disturbance on the Health of the Population of Blainville's Beaked Whales (Mesoplodon densirostris) in the Tongue of the Ocean
}

\author{
David Moretti \\ Navy Undersea Warfare Center (NUWC) \\ Newport, RI \\ Phone: (401) 832-5749 email: david.moretti@navy.mil \\ Len Thomas \& John Harwood \\ Centre for Research into Ecological and Environmental Modelling (CREEM) \\ University of St Andrews \\ St Andrews, UK \\ Diane Claridge \\ Bahamas Marine Mammal Research Organization (BMMRO) \\ Marsh Harbour \\ Abaco, Bahamas
}

Award Number: N0001412WX20427 / N00014W3WX20616 / N0001412WX20919

\section{LONG-TERM GOALS}

The primary objective of this research is to: Develop a predictive model for population health of Blainville's beaked whale (Mesoplodon densirostris, $M d$ ) in the Tongue Of The Ocean (TOTO), Bahamas, using data from passive acoustic monitoring collected around and during active sonar operations.

MFA sonar operations occur repeatedly on Navy ranges that are known to contain populations of Blainville's (Mesoplodon densirostris, $M d$ ) and Cuvier's (Ziphius cavirostris, Zc) beaked whales. Strandings of these species have been associated with the use of Navy sonar [1], [2]. A population of $M d$ is known to use the Atlantic Undersea Test and Evaluation Center (AUTEC) range in the Tongue Of The Ocean (TOTO), Bahamas [3], and a population of $Z c$ has been documented on the Southern California Offshore Range (SCORE) off San Clemente Island in California [4]. Developing a methodology for monitoring the long-term health of populations such as these, that are repeatedly exposed to sonar, is important for the continued operational integrity of these ranges.

This research focuses on $M d$ at AUTEC. It combines passive acoustic data from detection of $M d$ echolocation clicks and sonar, observational data from expert surface observers for group size, surface behavior, and age/sex compositions, biological data from biopsy sampling, precise ship 


\section{Report Documentation Page}

Form Approved

OMB No. 0704-0188

Public reporting burden for the collection of information is estimated to average 1 hour per response, including the time for reviewing instructions, searching existing data sources, gathering and maintaining the data needed, and completing and reviewing the collection of information. Send comments regarding this burden estimate or any other aspect of this collection of information,

including suggestions for reducing this burden, to Washington Headquarters Services, Directorate for Information Operations and Reports, 1215 Jefferson Davis Highway, Suite 1204, Arlington

VA 22202-4302. Respondents should be aware that notwithstanding any other provision of law, no person shall be subject to a penalty for failing to comply with a collection of information if it

does not display a currently valid OMB control number.

1. REPORT DATE

30 SEP 2014

4. TITLE AND SUBTITLE

The Effects of Behavioral Change in Response to Acoustic Disturbance on the Health of the Population of Blainville's Beaked Whales (Mesoplodon densirostris) in the Tongue of the Ocean

6. $\operatorname{AUTHOR}(\mathrm{S})$

7. PERFORMING ORGANIZATION NAME(S) AND ADDRESS(ES)

Navy Undersea Warfare Center (NUWC),1176 Howell

Street,Newport,RI,02841-1708

9. SPONSORING/MONITORING AGENCY NAME(S) AND ADDRESS(ES)
3. DATES COVERED

00-00-2014 to 00-00-2014

5a. CONTRACT NUMBER

5b. GRANT NUMBER

5c. PROGRAM ELEMENT NUMBER

5d. PROJECT NUMBER

5e. TASK NUMBER

5f. WORK UNIT NUMBER

8. PERFORMING ORGANIZATION

REPORT NUMBER

10. SPONSOR/MONITOR'S ACRONYM(S)

11. SPONSOR/MONITOR'S REPORT NUMBER(S)

12. DISTRIBUTION/AVAILABILITY STATEMENT

Approved for public release; distribution unlimited

13. SUPPLEMENTARY NOTES

14. ABSTRACT

15. SUBJECT TERMS

16. SECURITY CLASSIFICATION OF:

a. REPORT

unclassified b. ABSTRACT unclassified c. THIS PAGE unclassified
17. LIMITATION OF ABSTRACT

Same as

Report (SAR)
18. NUMBER OF PAGES

12 19a. NAME OF

RESPONSIBLE PERSON 
track data from sonar operations, and mid-term (days to months) satellite tag data for animal locations and dives.

It will use these data to inform a Population Consequence of Acoustic Disturbance (PCAD) model to predict the impact of repeated sonar exposure on population health.

\section{OBJECTIVES}

Same as the long-term goals.

\section{APPROACH}

Three overarching tasks must be completed to meet the objective.

1. Derive a risk function for $M d$ by combining passive acoustic detection data for $M d$ groups in the TOTO with sonar data archived during U.S. Navy operations.

2. Extend the data sets for an entire year to estimate the cumulative impact of repetitive sonar exposure as measured by the loss in foraging dives.

3. Develop a Population Consequences of Acoustic Disturbance (PCAD) model framework for $M d$ in the TOTO to estimate the effect of sonar on population health.

\section{WORK COMPLETED}

\section{Risk Function}

In FY14, the first empirical risk function that combines both passive acoustic $M d$ detection data with actual U.S. Navy sonar data was published (Figure 1) [5].

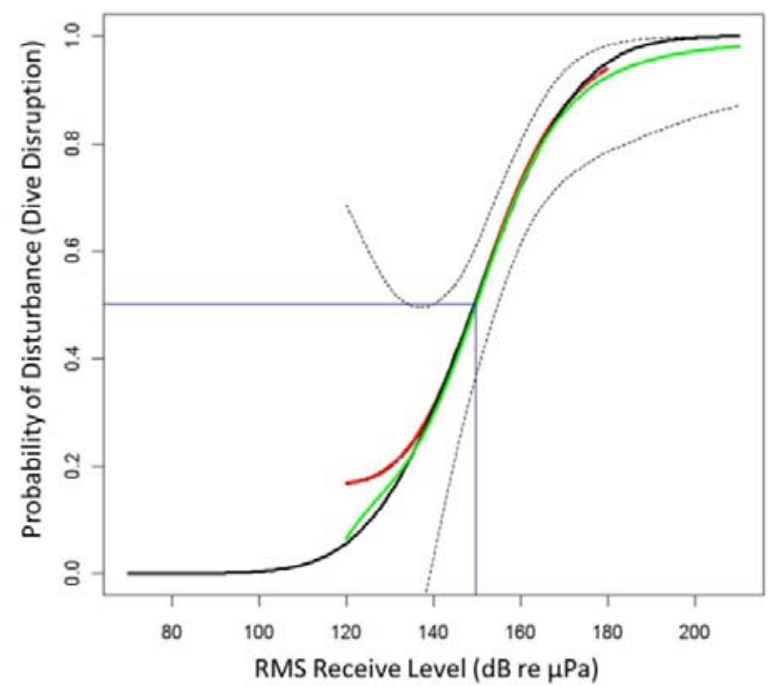

Figure 1. The probability of disturbance $\left(D_{r m s}\right)$ as a function of sonar $R L_{r m s .}$ The $G A M$ fit to the recorded data is shown in red with the bootstrap mean shown by the green with the point- 
wise 95\% confidence limits indicated by dotted lines from the bootstrap. The parametric GLM approximation is shown in black. There is a .5 probability of disturbance at a $R L_{r m s}$ of 149.8 $\mathrm{dB}$; this is indicated in blue.

A parametric expression was derived for the probability of disturbance $(P)$ and provided as follows:

$$
P[\text { disturbance }]=F\left(-8.073+.05407 R L_{r m s}\right)
$$

where $R L_{r m s}$ is the received level ( $\mathrm{dB}$ re $\mu \mathrm{Pa}$ ) and $F(z)$ is the cumulative normal distribution function [6].

Sonar and $M d$ passive acoustic data and ship track data from both 2011 and 2012 are now being analyzed. For example, ,a total of 240 hours of sonar per hydrophone was documented over the 2011 time period ( Figure 2). The estimated sound field during times of sonar activity for all sonar operations during these years was derived. These estimates, which include surface ship, dipping helo, and DICASS sonobuoy operations, were then combined with $M d$ group vocal periods (GVP) ( Figure 3).

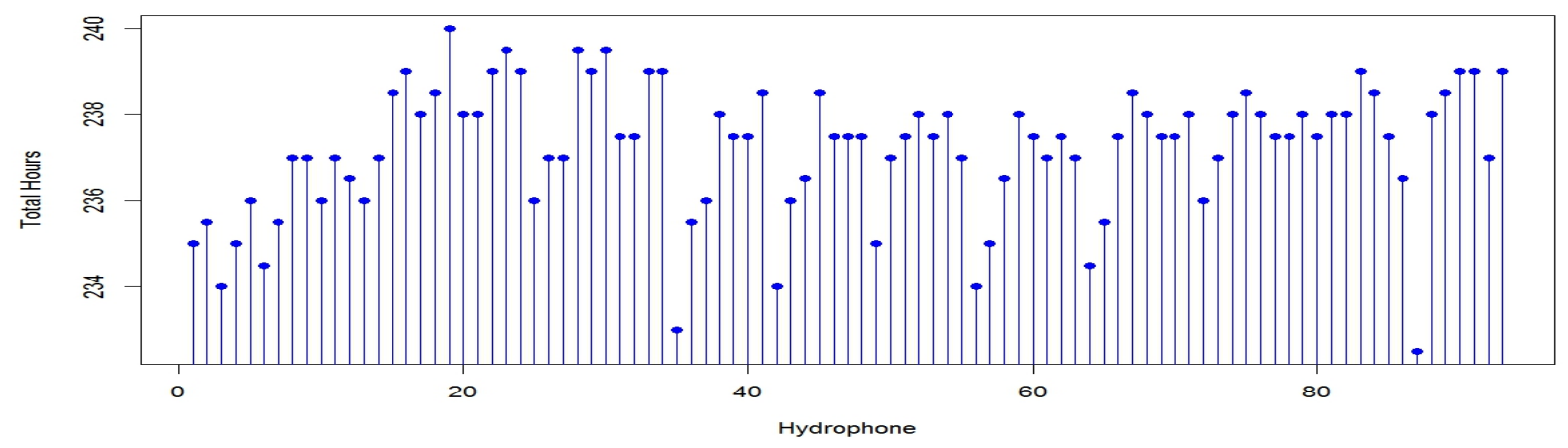

Figure 22011 total hours of sonar hours per hydrophone

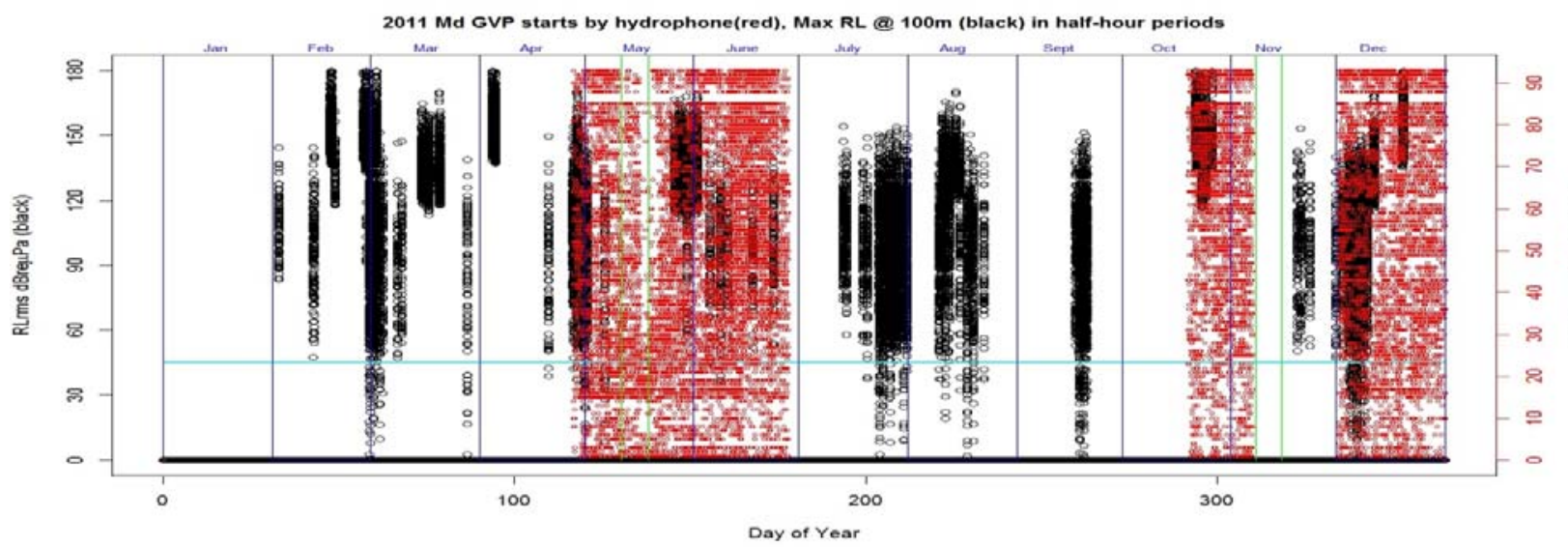

Figure 3: Md GVP center hydrophones (red) for times with archived. Each red dot represents a GVP on a particular hydrophone. The estimated maximum $R L_{r m s}$ in $d B r e \mu P a$ from surface ship, dipping helo, and DICASS sonobuoy operations for every range hydrophone, measured once per $1 / 2$ hr at a depth of 100m depth (black) during 2011 
Data on Md responses to lower-level sources may facilitate extension of the empirical risk function to lower RLs. The methods used to develop the risk function were applied to 2011 and 2012 data for 53C surface ship sonar, dipping helo and DICASS sonobuoys. The function generated using surface ship sonar data closely matched the risk function presented in Moretti et al. 2014. However, the curve produced from the sonars with lower source levels was shifted $\sim 10 \mathrm{~dB}$ lower with a 0.5 probability of disturbance at $140 \mathrm{dBre} \mu \mathrm{Pa}$ rather than $150 \mathrm{dBre} \mu \mathrm{Pa}$ for surface ship sonar (Figure 4). This may be due tothe distance from the source to the animal for a given RL.
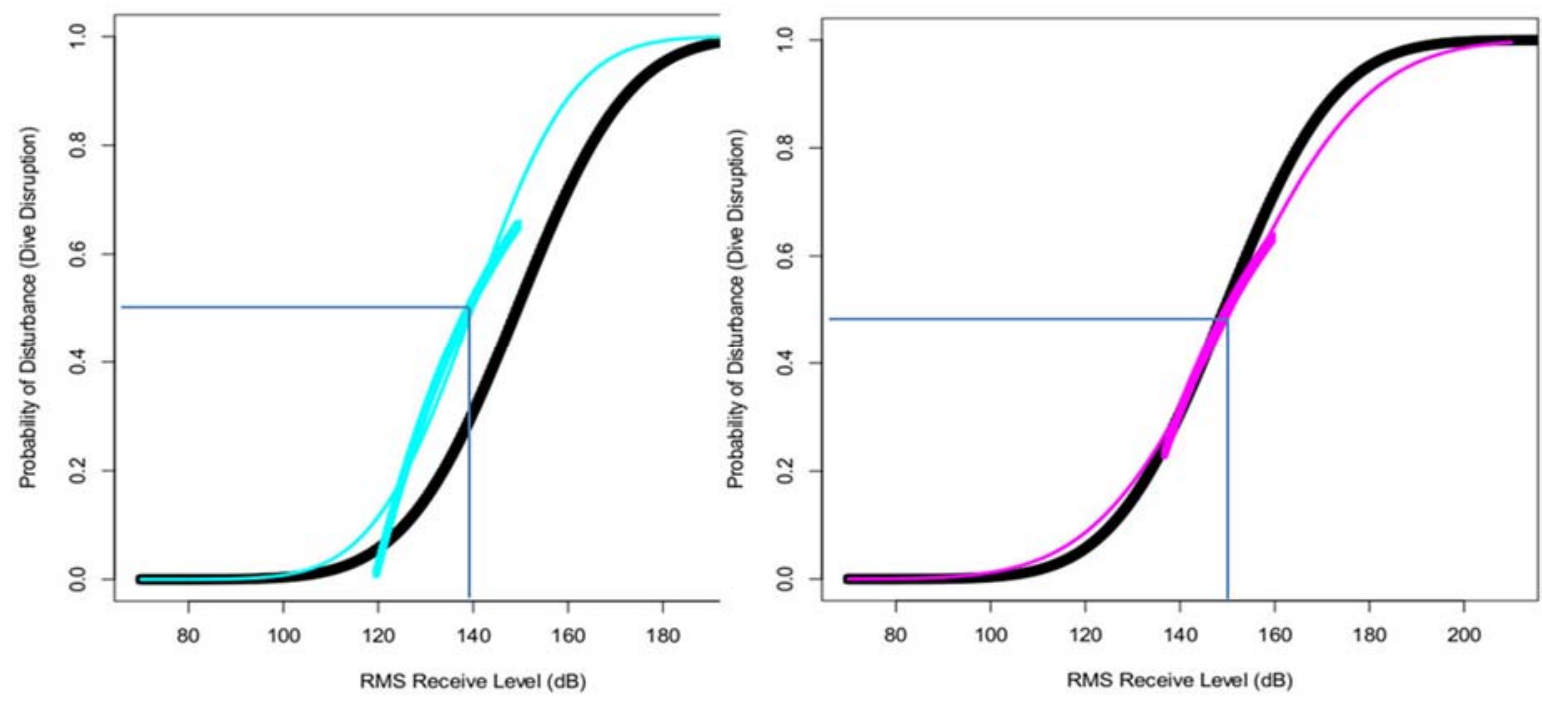

Figure 2: $\quad$ The probability of Md behavioral disturbance (dive disruption) as a function of $R L_{r m s} d B r e \mu P a$ for dipping helo (left/cyan) and surface ship (right/pink) sonar. The GLM fit to the data is shown as a thin line of the same color. The published Md risk function is shown in black.

This raises additional questions. Does a source in close proximity to an animal elicit a response at a lower RL? Does the mode of operation effect the response? Both dipping helo and DICASS sonobuoys drop suddenly from the sky, whereas the RL from a surface ship sonar changes dynamically as the source moves relative to the animal [7].

\section{Cumulative Effect}

The Bahamas Marine Mammal Research Organization (BMMRO) study site lies off the southern shore of Abaco in an area where $M d$ are not regularly exposed to Navy sonar. It therefore provides a valuable comparison site for animals in the TOTO. Analysis of data from photoidentification (Figure 5), genetic and chemistry markers from biopsy samples, and telemetry tags suggests the Abaco animals represent a separate population with little to no mixing between Abaco and the TOTO $[8,3]$. 


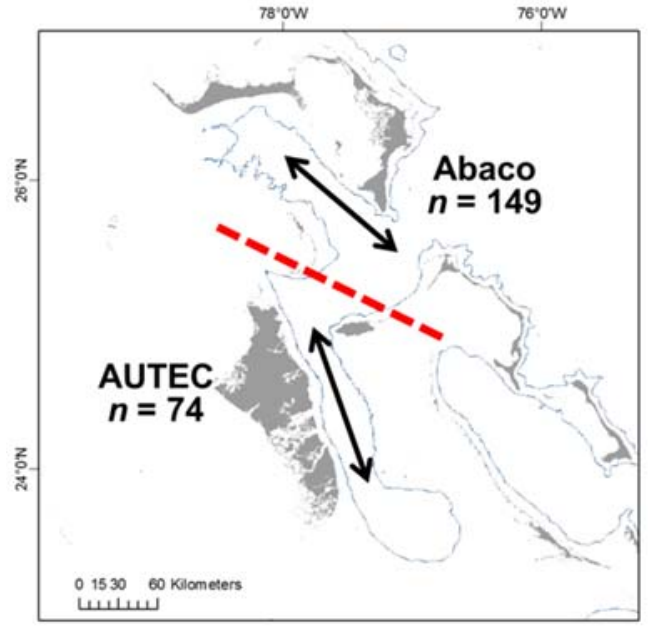

Figure 3: Movements of Md within AUTEC and Abaco documented using photo-ID (black arrows) provide no evidence of exchange between the two areas; $n=$ number of known individuals in each area.

Initial results, presented by Claridge (2013), indicate that the ratio of adult females to calves and juveniles on AUTEC is lower than at Abaco (Figure 6) [3]. The reasons for this demographic difference are currently unclear, making further analysis of the potential population consequences of $M d$ responses to sonar critical [9, 10,11].

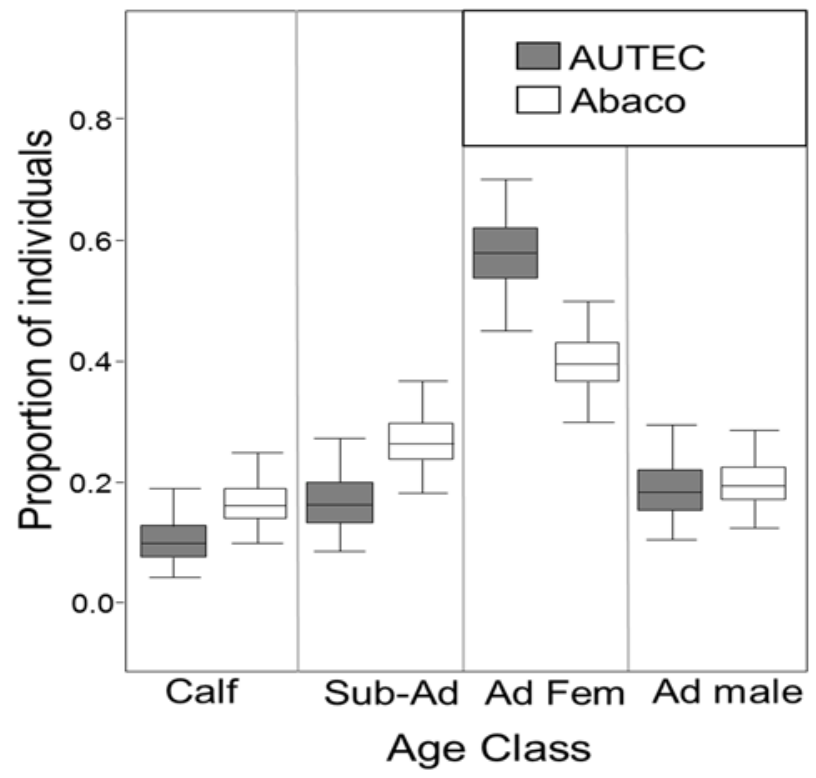

Figure 4: Md stage composition at AUTEC and Abaco (Claridge, 2013).

Movement of $M d$ in response to sonar operations at AUTEC have been documented [9, 10, 11]. In 2012, over 23 days of surface ship sonar took place. During these operations, sonar was transmitted for a total of 126 hours. Low level (DICASS/Dipping Helo) sonar accounted for an additional $60 \mathrm{hr}$ of sonar transmission over 39 days. The number of foraging dives lost is being estimated using GVPs as a proxy. Md GVPs during times when no sonar was present are being 
identified to estimate the average undisturbed GVP rate. This GVP rate, will be compared to the to the rate measured during exercises to estimate the cumulative disruption of foraging dives. These results will be used in the estimation of population level effects.

The initial population-level analysis will use a modified version of the model described in New et. al (2013), informed by the estimates from AUTEC. The initial model will provide a means of exploring the sensitivity of the population to dive disruptions based on the spatial displacement measured during sonar operations. The worst case assumption is that animals do not forage during the entire period they are displaced from the range.

Satellite tags are also being used to explore $M d$ dive behavior around operations. To date, tags have been placed on 4 animals around operations and the data are currently being analyzed (Figure 57). These animals moved away from the range during the period of sonar activity, and returned upon cessation of sonar, suggesting that the range is an important foraging area for these animals.
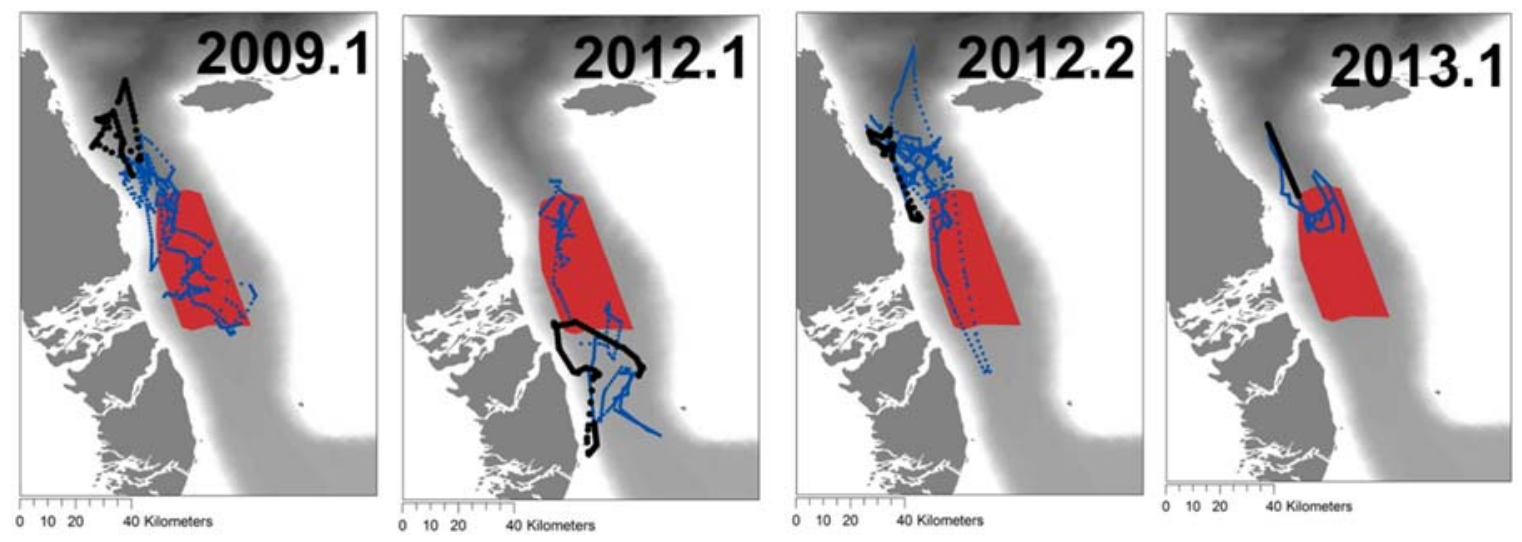

Figure 5: Movements of 1 adult male (2009) and 3 adult females, tagged in separate groups, during multi-day exercises with sonar (black lines), and after the exercises (blue lines). AUTEC is shown in red with the TOTO in gray. (Courtesy of J. Durban).

In order to estimate the number of animals present on the range, potential GVPs were identified from 2011 and 2012 M3R detections [12]. The analysis was restricted to groups which were detected on inner-range hydrophones to ensure a high probability of detecting foraging groups of animals. The output was further filtered to remove GVPs that were identified using fewer than 500 clicks from all hydrophones. The mean $M d$ inter-click interval (ICI) is $\sim 0.3$ seconds, so 500 clicks on a single phone represent a duration of less than a 3 minutes. Therefore, these were deemed unlikely to be produced during a successful deep foraging dive Figure 6 . The range hydrophones are designed to detect a $37 \mathrm{kHz}$ pinger at 194 dB (equivalent to an $M d$ group for which the on-axis echolocation click source level is in excess of $200 \mathrm{~dB}$ ), it is therefore highly likely that a GVP will be detected on more than one hydrophones. Consequently, GVPs that were detected on only one hydrophone were eliminated. 

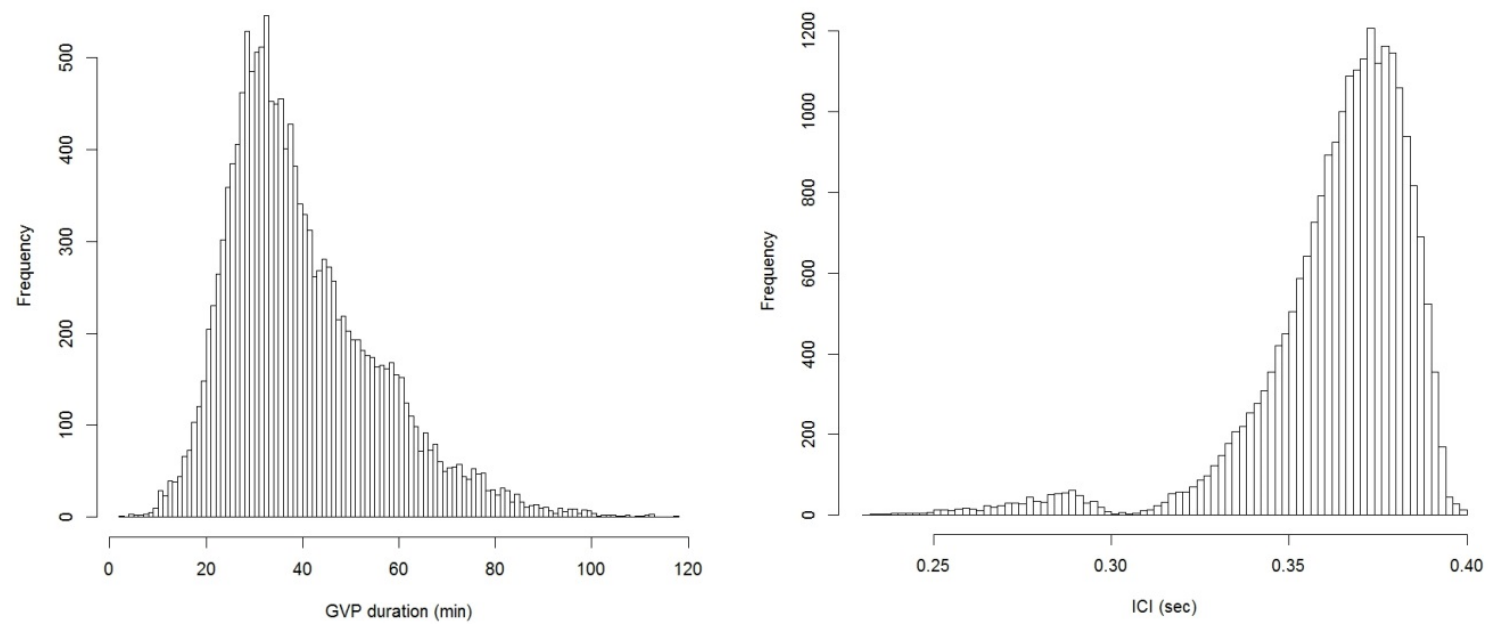

Figure 6: GVP duration (right) and Inter-Click Interval (ICI) from 2012 filtered GVP output data.

$M d$ density is being estimated using the dive counting method described in Moretti et al., 2010 [9]. To validate the auto-detection of GVPs, 200 were randomly sampled from the archives and spectrograms for each sample were validated by a trained analyst. The true positive rate was estimated to be 0.95 , and it was concluded that no dives on the range were missed.

These results were used to estimate variaitons in the density of $M d$ within the range boundaries over the course of the year (Figure 9).

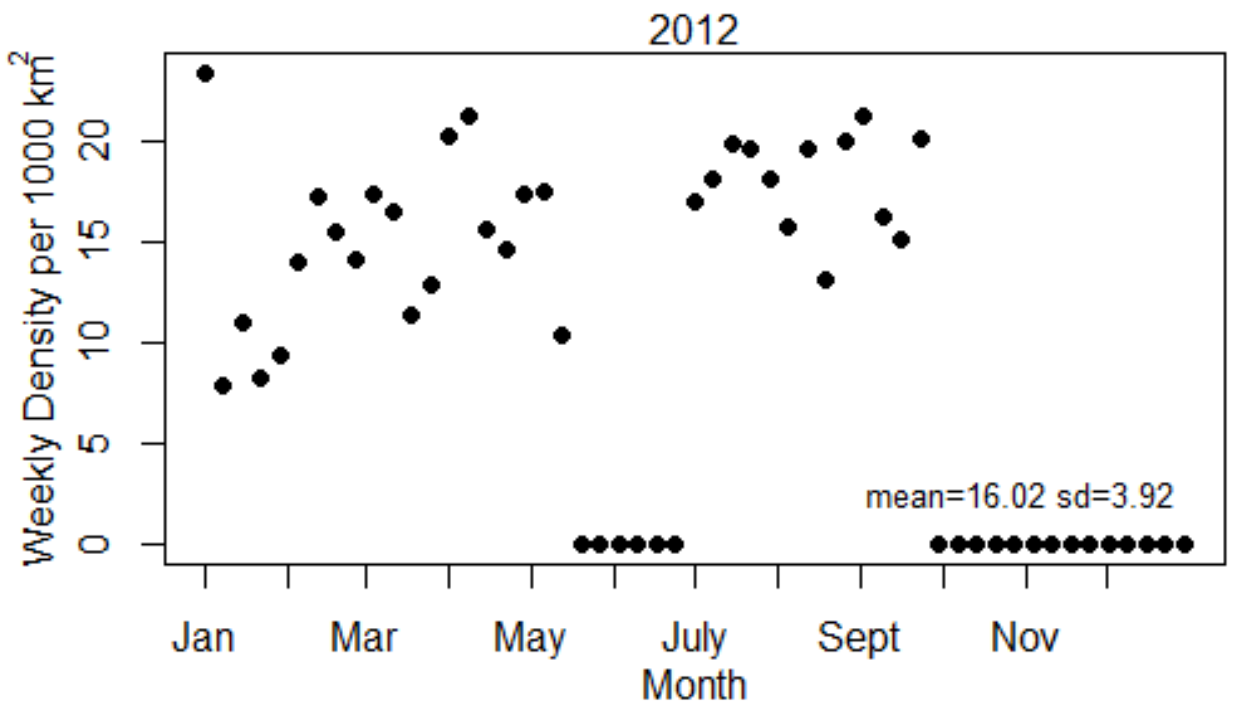

Figure 7: Weekly estimates of Md density during 2012, based on dive counting. Zero values are for times when there are no M3R detection archives.

\section{PCAD Model}

A generalized beaked whale PCAD model, which uses an energetics approach, is described in 
New et al. (2013) [13]. This model is being adapted to use estimates of the cumulative number of lost foraging dives for $M d$ in the TOTO derived from passive acoustic and satellite data as described above. The output of the model will provide insight as to the extent that displacement due to sonar may affect the ratio of adult females to calves and juveniles.

The model uses an energetic approach. For this case study, the number of dives lost is being used as a proxy for calories lost. If animals remain over the field of hydrophones, the change in dive rate can be inferred using the detection of GVPs as described above. For time $s$ of displacement, tags are being used to directly measure animal movement and dive behavior.

An additional data gap exists regarding the distribution of prey. Both the passive acoustic and tag data indicate that animals are displaced during sonar operations. If they continue to forage but there is a reduction in available prey off-range, this displacement may be significant. During the BRS in 2008, prey field mapping with a surface transducer was undertaken and the data were compared to the distribution of $M d$ groups as derived from M3R passive acoustics [14]. No subsequent effort has been made to map deep $(>800 \mathrm{~m})$ benthic prey at AUTEC, the depths at which $M d$ are foraging. Of particular importance would be mapping prey along the western edge of TOTO where whales appear to be displaced to during periods of sonar use on the AUTEC range.

\section{RESULTS}

An empirical risk function has been completed and published. A year of data required to calculate the cumulative effect of sonar has been compiled. This includes estimates of group positions based on passive acoustic detectons of $M d$ dive starts, sonar transmission times and types (as measured on the hydrophones), along with precise ship tracks provided by AUTEC. The latter data were used in conjunction with the CASS/GRAB propagation model to estimate the sound field during each operation [15].

The number of dives lost due to displacement over the entire year and the number of animals affected is being estimated using passive acoustic data. The generalized beaked whale PCAD model [13] will be modified to use the data available from AUTEC. This will provide a framework for long-term monitoring of population health.

The robustness of predictions from this model will depend heavily on the reliability of predictions of the level of dive loss due to sonar exposure. There is an active program underway at AUTEC to attach dive recording satellite tags to $M d$ around sonar operations To date, four tags have been place on animals around operations, and one was place with no sonar present. In addition, in 2014, a tag was placed on an adult female Cuvier's beaked whale that moved rapidly to an area south of the range when sonar exercises commenced (Figure 10). Placement of these tags is extremely difficult since the animals are deep diving, have cryptic surface behaviors, and do not present a large surface profile. Tests with an emphasis on tag placement are planned for FY15 with the goal of increasing the number of tags deployed. 


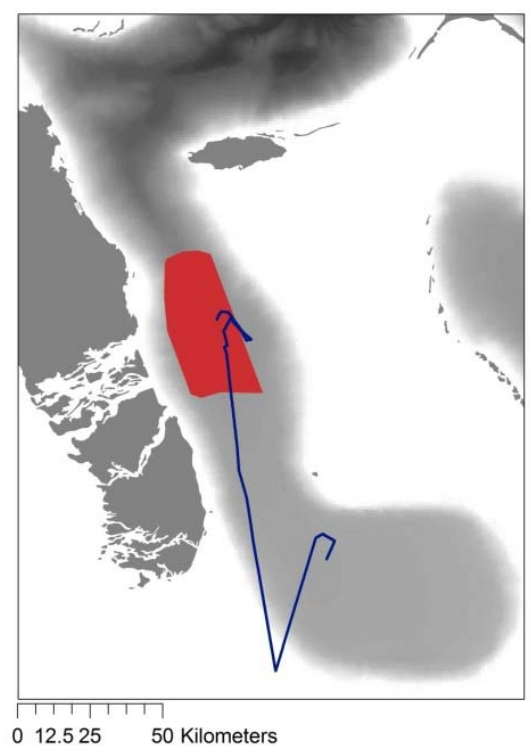

Figure 8. Satellite track of a Cuvier's beaked whale around an MFA sonar operations (Courtesy of J. Durban)

A test with a deep diving prey mapper is planned for the summer of 2015 for both the AUTEC and Abaco sites. This will provide data on the distribution of prey at typical foraging depths both within and outside the range boundaries and at the Abaco comparative site.

\section{IMPACT/APPLICATIONS}

This effort is focused on developing a means of estimating the population health of $M d$ in the TOTO. The long-term monitoring of cetaceans in areas of repeated sonar use is a mandated component of the Navy's environmental compliance requirements. If successful with $M d$, this methodology can be adapted to other Navy ranges and sonar-sensitive beaked whale species including Cuvier's (Ziphius cavirostris) beaked whales at SCORE.

\section{RELATED PROJECTS}

\section{Marine Mammal Monitoring on Navy Ranges (M3R)}

The basic opportunistic passive acoustic data with and without MFA sonar present for vocalizing groups of $M d$ are being collected through the M3R program. Two major multi-ship sonar exercises per year at AUTEC will be monitored. The program is also providing the basic signal processing infrastructure and algorithms which make the collection and analysis of these data possible. This includes isolation of the sources present, their location, and transmission durations. These data are then being integrated with precise AUTEC vehicle track which allow an understanding of the interaction of active sources with ship movements relative to vocalizing and tagged animals. This attention to context is extremely important and is often overlooked in the discussion of interaction of sonar and marine mammals. 
The ability to obtain precise ship track and at the same time extract precise detail as to the use of MFA sonar is unprecedented. Depending on the circumstances, some data may be classified. M3R is providing the necessary processes to handle these data in the appropriate manner and providing the final outputs via the specified Navy release chain.

M3R is providing in-kind support in excess of $\$ 200 \mathrm{~K}$ per year. These data are also being used as part of the LATTE program the results of which will be incorporated into this program.

\section{The ONR PCAD Working Group}

ONR has funded the University of California, Santa Barbara (led by Erica Fleishman) to convene a collaborative Working Group of researchers (including two of the PIs on this proposal) who will cooperate and meet regularly to examine the population-level effects of sound exposure on marine mammals. The objectives of that group include, but are not limited to:

- Explore how the conceptual model developed by the NRC committee might be translated into a formal mathematical structure

- Consider how the above model might be parameterized with existing or emerging data on the responses of large vertebrates to disturbance

- Define conceptual approaches for investigating transfer functions (e.g., time-energy budgets, trait-mediated responses)

- Expand work by the NRC to include sensitivity analyses on different transfer functions

- Outline exploratory models that might be used to model transfer functions, synthesize existing knowledge, examine potential mechanisms, or inform research and management efforts

The Working Group meets at 6-monthly intervals and has already developed PCAD-style models for elephant seals and coastal bottlenose dolphins, and will begin the development of a similar model for beaked whales at its spring 2011 meeting. The mathematical structure developed by the Working Group will be applied as part of this program. Two of the PIs associated with this proposal are members of the Working Group and they will ensure that the project's outputs are harmonized with the needs of the Working Group.

\section{Density Estimation for Cetaceans from Acoustic Fixed sensors (DECAF)}

One required input for the proposed project is an estimate of the number of animals present within the AUTEC range under different circumstances (for example, before, during and after exercises). Methods for estimating absolute animal density from fixed hydrophone data have been developed under the above project, and applied to estimate beaked whale density (and hence numbers) at AUTEC. This project, which will finish in May 2010, was co-funded under the National Oceanographic Partnership Program by the Joint Industry Program of the Association of Oil and Gas Producers and by the National Oceanographic and Atmospheric Administration; the project budget is US $\$ 1,500 \mathrm{~K}$.

\section{Linking Acoustic Tests and Tagging using statistical Estimation: Modeling the Behavior of Beaked Whales in Response to Medium Frequency Active Sonar (LATTE)}

Another essential input is an estimate of the behavioral response of beaked whales at AUTEC, in terms of their change in diving behavior and location. Methods to estimate this using combined 
tag and passive acoustic data are being developed in the LATTE project, which runs from April 2010 to March 2013. The output will be a statistical description of the animal behavioral response, produced using all available relevant data. The framework used to produce the parameterized model can be used in the project proposed here to further refine the parameter estimates as new data are produced. The LATTE project is funded by ONR and has a budget of US $\$ 1,250 \mathrm{~K}$.

\section{The Way They Move}

The LATTE project is leveraged on parallel work taking place at the University of St Andrews to develop statistical methods for fitting movement models to tag data from mammals. This project is funded from September 2008 to August 2011 by the UK Engineering and Physical Science Research Council, with a budget of approximately US\$650K.

\section{REFERENCES}

[1] A. D'Amico, R. Gisiner, D. Ketten, J. Hammock, C. Johnson, P. Tyack and J. Mead, "Beaked whale strandings and naval exercises," Aquatic Mammals, vol. 35(4), pp. 435-444, 2009.

[2] G. England, D. Evans, C. Lautenbacher, S. Morrissey, W. Hogarth and H. Johnson, "Joint Interim Report, Bahamas Marine Mammal Stranding Event, 15-16 March, 2000," U.S. Department of Commerce, U.S. Secretary of the Navy, 2001.

[3] D. E. Claridge, Population Ecology of Blainville's Beaked Whales (Mesoplodon densirostris), PhD Thesis, University of St. Andrews, 2013.

[4] E. Falcone, G. Shorr, A. Douglas, J. Calambokidis, E. Henderson, M. McKenna, J. Hildebrand and D. Moretti, Sighting characteristics and photo-identification of Cuvier's beaked whales (Ziphius cavirostris) near San Clemente Island, California: a key area for beaked whales and the military?, vol. 156, Marine Biology, 2009, pp. 2631-2640.

[5] D. Moretti, L. Thomas, T. Marques, J. Harwood, A. Dilley, B. Neales, J. Ward, E. McCarthy, L. New, S. Jarvis and R. Morrissey, "A risk funciton fo Blainville's beaked whales ("Mesoplodon densirostris") derived from Mid-Frequency Active (MFA) sonar operations," PLoS ONE, vol. 9, no. 1, 2014.

[6] S. R. Bowling, M. T. Khasawneh, S. Kaewkuekool and B. R. Cho, "A logistic approximation to the cumulative normal distribution," Journal of Industrial Engineering and Management, vol. 2, no. 1, pp. 114-127, 2009.

[7] S. L. DeRuiter, B. L. Southall, J. Calambokidis, D. Sadykova, E. A. Falcone, A. S. Friedlaender, J. E. Joseph, D. Moretti, G. S. Schorr, L. Thomas and P. Tyack, "First direct measurements of behavioural response by Cuvier's beaked whales to mid-frequency active sonar," Biology Letters, vol. 9, no. 4, 23 August 2013.

[8] D. E. Claridge, Fine-scale distribution and habitat selectin of beaked whales, Masters of Science Thesis, University of St. Andrews , 2006.

[9] D. Moretti, T. Marques, L. Thomas, N. DiMarzio, A. Dilley, R. Morrissey, E. McCarthy, J. Ward and S. Jarvis, A dive counting density estimation method for Blainville's beaked whale (Mesoplodon densirostris) using a bottom-mounted hydrophone field as applied to a MidFrequency Active (MFA) sonar operation, vol. 71(11), 2010, pp. 1036-1042. 
[10] E. McCarthy, D. Moretti, L. Thomas, N. DiMarzio, A. Dilley, R. Morissey, J. Ward and S. Jarvis, "Changes in Spatial and Temporal Distribution and Vocal Behavior of Blainville's Beaked Whales (Mesoplodon densirostris) during Multi-Ship Exercises with MidFrequency Sonar," Marine Mammal Science, vol. 27, no. 3, pp. E206-E226, 2 July 2011.

[11] P. Tyack, W. Zimmer, D. Moretti, B. Southall, D. Claridge, J. Durban, C. Clark, A. D'Amico, N. DiMazio, S. Jarvis, E. McCarhy, R. Morrissey, J. Ward and I. Boyd, "Beaked Whales Respond to Simulated and Actual Navy Sonar," PLos ONE, vol. 6, no. 3, 2010.

[12] S. M. Jarvis, R. P. Morrissey, D. J. Moretti and N. A. S. J. A. DiMarzio, "Marine Mammal Monitoring on Navy Ranges (M3R): A Toolset for Automated Detection, Localization and Monitoring of Marrine Mammals in Open Ocean Environments," Marine Technology Society Journal, vol. 48, no. 1, 2014.

[13] L. F. New, Moretti, David J., Hooker, Sascha K. and Simmons, Samantha E., "Using energetic models to investigate the survival and reproduction of beaked whales (family Ziphiidae)," PLoS One, vol. 8, no. 7, 2013.

[14] E. L. Hazen, D. P. Nowacek, L. St. Laurent, P. N. Halpin and D. J. Moretti, "The Relationship among Oceanography, Prey Fields, and Beaked Whale Foraging Habitat in the Tongue of the Ocean," PLoS ONE, vol. 6, no. 4, 2011.

[15] H. Weinberg and R. Keenan, "Gaussian ray bundles for modeling high frequency propagation loss under shallow-water conditions," The Journal of the Acoustical Society of America, vol. 100, pp. 1421-1431, 1996.

[16] D. Moretti, L. Thomas, T. Marques, J. Harwood, A. Dilley, B. Neales, J. Ward, E. McCarthy, L. New, S. Jarvis and R. Morrissey, "A risk funciton for Blainville's beaked whales ("Mesoplodon densirostris") derived from Mid-Frequency Active (MFA) sonar operations". 